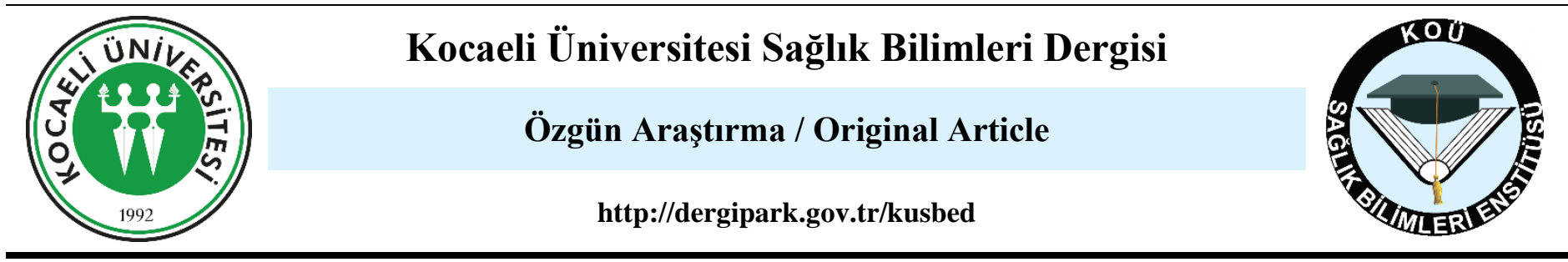

\title{
FGFR1 SER777 MUTASYONU VE MESANE KANSERI
}

\author{
FGFR1 SER777 MUTATION AND BLADDER CANCER
}

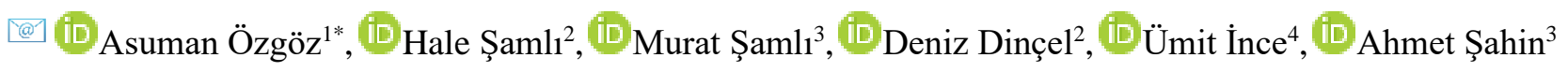

\begin{abstract}
${ }^{1}$ Kastamonu Üniversitesi, Tıp Fakültesi, Dahili Tıp Bilimleri Bölümü, Tıbbi Genetik Anabilim Dalı, Kastamonu, Türkiye, ${ }^{2}$ Bursa Uludağ Üniversitesi, Veteriner Fakültesi, Zootekni ve Hayvan Besleme Bölümü, Genetik Anabilim Dalı, Bursa, Türkiye, Acıbadem Mehmet Ali Aydınlar Üniversitesi, Tıp Fakültesi, Cerrahi Tıp Bilimleri, ${ }^{3}$ Üroloji Anabilim Dalı; ${ }^{4}$ Patoloji Anabilim Dalı, İstanbul, Türkiye
\end{abstract}

ORCID iD: Asuman Özgöz: 0000-0003-4018-5807; Hale Şaml1: 0000-0003-4728-0735; Murat Şaml1: 0000-0001-6650-3880; Deniz Dinçel: 00000002-8015-9032; Ümit İnce: 0000-0002-6113-661X; Ahmet Şahin: 0000-0003-1354-988X

*Sorumlu Yazar / Corresponding Author: Asuman Özgöz, e-posta / e-mail: biologistasu @ gmail.com

Geliş Tarihi / Received: 24.09 .2020

Kabul Tarihi / Accepted: 09.02.2021

Yayım Tarihi / Published:29.05.2021

\section{$\ddot{O} z$}

Amaç: ERK 1/2 (ekstraselüler sinyalle düzenlenen kinaz 1,2) ve p38a'nın, FGFR1 Ser 777'yi fosforile etmek yoluyla anti-tümörojenik etki göstermesi muhtemeldir. Ser777 fosforilasyonunun ise FGFR1 aktivasyonunu inhibe ettiği bilinmektedir. Dolayısıyla Ser777'nin mutasyona uğramasının FGFRl'i aktive ederek; karsinogenez ile bunu devam ettirebilecek mekanizmaları harekete geçirebileceği düşünülmüştür. Bu kapsamda gerçekleştiren çalışmada; mesane kanseri ile FGFR1 Ser777 mutasyonu arasındaki ilişkinin tespiti amaçlanmıştır.

Yöntem: Çalışmada; mesane kanseri tümör dokusu $(\mathrm{n}=62)$ ve kontrol grubu örneklerinde (n=30) DNA izolasyonunun ardından, FGFRI Ser777 mutasyon analizi, DNA dizi analizi yöntemi ile gerçekleştirilmiştir.

Bulgular: Bildiğimiz kadarıyla ilk defa çalışılan söz konusu mutasyon, incelenen hasta ve kontrol grubu örneklerinde tespit edilememiştir.

Sonuç: Elde edilen bulgular, Ser777'nin mesane kanserinde mutasyona uğramadığını düşündürmüştür. Literatürde konuyla ilgili başka çalışma bulunmadığı göz önüne alındığında, çalışma sonuçlarının literatüre önemli katkı sağlayabileceği düşünülmektedir. Dahası, diğer kanser türlerinde de FGRF1 Ser777 mutasyonunun çalışılmasının farklı bakış açıları ortaya koyabileceğini düşünmekteyiz.

Anahtar Kelimeler: Dizi analizi, FGFR1, Mesane Kanseri, Ser777.

\begin{abstract}
Objective: The ERK 1/2 (extracellular signal-regulated kinase 1,2) and p38 $\alpha$ probably have an anti-tumorigenic effect by phosphorylating FGFRI Ser 777. The Ser777 phosphorylation is known to inhibit FGFR1 activation. Therefore, the Ser777 mutation was suggested to trigger the carcinogenesis, and the other continued mechanisms by activating the $F G F R$ were suggested. We aimed to determine the relationship between FGFR1 Ser777 mutation and bladder cancer were aimed to be determined in this context.

Methods: After the DNA isolation of bladder cancer tumor tissues $(n=62)$ and control group samples $(n=30)$, the DNA sequence analysis was performed for the FGFR1 Ser777 mutation in the study carried out for this purpose.

Results: The mutation which has been studied for the first time to the best of our knowledge was not detected in the patient and control group samples in the current study.

Conclusion: As a conclusion the data suggested that Ser777 did not mutate in bladder cancer. Considering that there are no other studies on the subject in the literature, it is thought that the results of the study might make a significant contribution to the literature. Moreover, in our opinion, studying the FGRF1 Ser777 mutation in the other types of the cancer will reveal different points of view.
\end{abstract}

Keywords: Sequence analysis, FGFR1, Bladder cancer, Ser777. 


\section{Giriş}

Mesane kanseri batılı ülkelerde, erkekler arasında 4., kadınlarda ise 8 . en s1k görülen kanser türüdür. ${ }^{1}$ Mesane kanserinde her y1l 300.000 yeni olgu tespit edilmektedir. ${ }^{2}$ Ürotelyal mesane kanserinin, patolojik, genetik ve epigenetik düzeylerde farklı özellikleri olduğu izlenmektedir. ${ }^{3}$ Mesane kanseri patofizyolojisinin invazif ve non-invazif vakalarda farklılık göstermesine karşın; hücre döngüsü, P3K sinyal, histon modifikasyon, SWI/SNF nükleozom yeniden modelleme gibi yolaklarda görevli onkogenik (MDM2, Myc, Ras, ERBB-2, PI3KCA..vb) ve tümör baskılayıc1 genlerde (PB, p53, SFRP1, PTEN, CDKN2A..vb) meydana gelen bir takım değişimler sonucu şekillendiği bilinmektedir. ${ }^{4,5}$

DNA tamir yolağı genleri ERCC2, FANCC, ATM ve RB1'deki mutasyonların mesane kanserinde neoadjuvan kemoterapiye tam patolojik yanıtla ilişkili olduğu ve klinik karar vermedeki yararları açısından değerlendirilmesinin gerektiği bildirilmektedir. Reseptör tirozin kinaz (RTK)MAPK ve PI3K-MTOR yolaklarındaki gen mutasyonları, kopya sayısı varyasyonları ve yeniden düzenlenmeler mesane tümörlerinin yaklaşık \%70'inde bulunmakta olup; son çalışmalarda, bu değişikliklerin prognostik açıdan önemli olmanın yanı sıra, tedaviye cevabın tahmininde etkili olabileceği belirtilmektedir. ${ }^{6}$

$\mathrm{Bu}$ değerlendirmeler göze alındığında RTK ailesi üyeleri olan FGFR'lerin mesane kanserinde çalışılmasının önemi anlaşılmaktadır.

Fibroblast büyüme faktörü reseptörleri (FGFR'ler) ve reseptör tirozin kinazlar pek çok kanser türüyle ve farklı patolojik durumlarla ilişkilidir. $\mathrm{Bu}$ sebeple, $F G F R^{\prime}$ lerin düzenleyici mekanizmalarının anlaşılması araştırma, ilgi konusu olmuştur. Dört adet birbiriyle yakın ilişki içinde olan $F G F R$ reseptörünün (FGFR1-FGFR4), proliferasyon, diferansiyasyon, migrasyon ve hücrelerin yaşam süresinde önemli görevleri mevcuttur. ${ }^{7}$

FGFR'leri yüksek derecede etkileyen ve aktive eden 18 FGF ligandı mevcuttur. Bu aktivasyon, FGF'ler onları dimerize etmek için $F G F R$ 'lere bağlandığında gerçekleşir ve sonuç olarak, FGFR tirozin kinaz domaini aktive olarak, $F G F R$ 'nin yedi tirozin rezidüsünden transfosforile edilmiş olur. ${ }^{8,9}$ Reseptör bir kez aktive edildiğinde, FGFR substrat 2a (FRS2a), PLC-g gibi pek çok intraselüler proteini de, fosforile etmek suretiyle aktifleştirir. ${ }^{10}$

FGFR, FRS2a'y1 fosforile ettiğinde, Src homoloji 2 (SH2) domain-içeren protein tirozin fosfataz-2 (SHP2)'ye özel iki bağlanma bölgesi ve büyüme faktörü reseptörüne-bağlanan protein 2 (GRB2)'ye özel dört bölgeye bağlanma gerçekleşir. Bunu takiben, GRB2'nin SH3 bölgesi, SOS ve GAB1 adındaki iki proteine bağlanarak, MAPK ve PI3KAkt sinyal yolaklarını aktive etmek üzere bir kompleks oluşturur. ${ }^{10}$ Aktif $F G F R$ 'ler tarafından indüklenen pek çok başka yolak da mevcuttur, bu yolakların indüklenmesiyle MAPK'ler, p38, JNK ve STAT gibi proteinlerin kontrolü gerçekleştirilir. ${ }^{11,12}$ FGFR aktive olarak, pek çok sinyal yolağıyla etkileşmesinin yanında, MAPK sinyali ve FRS2a'nın treonin fosforilasyonuyla da deaktive edilebilir ki bu mekanizmalar ERK1 ve ERK2 tarafından kontrol edilirler. ${ }^{13}$

FGFRl'in 755 'den 822 'e kadar olan amino asitleri de içeren C-terminalinde pek çok serin mevcuttur; FGFR sinyalinin spesifik serin fosforilasyonu yoluyla düzenlenmesinin muhtemel olduğu düşünülmüştür. Yabanıl tip FGFRl'in aktif ERK1 ve ERK2 formları tarafından fosforile edildiği saptanırken, S777A ve S777D'de kritik serin mutant proteinlerin fosforile edilmediği saptanmıştır. $^{7}$

FGF1'in ekstraselüler bölgeden, hücrenin sitozolüne ve nükleusuna geçme özelliğinin mevcut olması, rRNA sentezi ve hücre büyümesi gibi pek çok olayı kontrol edebilmesini sağlamaktadır. FGF1'in bu translokasyonu, FGFRl'in Cterminal kuyruğunda bulunan Ser777'nin p38 MAPK tarafindan fosforile edilmesi, dolayısıyla aktive edilmesiyle gerçekleşir. Bununla birlikte, eğer Ser777 mutantsa (S777A), bu mutant FGFR1 p38 MAPK tarafindan fosforile edilip, aktive edilemez. ${ }^{14,15}$

Özetle literatürde FGFR1 Ser777 mutasyonunun hücre bölünmesi/üremesi ve hücresel migrasyona etki ederek karsinogenezde etkili olacağı sonucuna varılmıştır, fakat bu mutasyonlar sadece hücre hatlarında ve amino asit düzeyinde gösterilmiş olup, nükleotid değişimi kontrol edilmemiştir. ${ }^{7,15}$

Sørensen ve ark., çalışmalarında COS-1 (maymun böbrek dokusu fibroblast benzeri hücre hattı) hücrelerini yabanıl tip FGFRl ve nokta mutasyonlar1 bulunan FGFRl (FGFRl S777A, FGFRl S777D, FGFRl S777E, FGFRl S777N) ile transfekte etmişler ve sonrasında FGF1'in in vivo fosforilasyonunu ve total FGF1 miktarını analiz etmişlerdir. Çalışma sonucunda, FGFRl S777D ve FGFRl S777E'nin FGF1 translokasyonunu sağlarken, FGFR1 S777A ve FGFR1 S777N sağlayamadığı ve fosforile edilmiş Ser777'nin FGF1 translokasyonu için gerekli olduğunun düşünüldüğü bildirilmiştir. Ayrıca çalışmanın devamında, p38 MAPK'nın düzenlediği FGFR1 Ser777 fosforilasyonunun FGF1'in hücrelere translokasyonunun düzenlenmesinde önemli olduğu düşünülmüştür. ${ }^{15}$

Muhtemelen fosforile edilmiş Ser777, FGF1'in translokasyonunu kontrol eden bir mekanizmadır. Çünkü Kostas ve ark.'nın daha sonra yaptıkları bir çalışmada, FGF1'in hücre içine translokasyonunun hücreleri apopitoza karşı koruduğu ve hücre sağkalımını (sürvisini) desteklediği ve sadece $F G F R$ 'ye bağıml sinyalizasyonun elimine edilmesi değil ayn1 zamanda FGF1 veya FGF2 translokasyonunun engellenmesinin de FGFR eksprese eden kanser hücrelerinin apopitozunu etkili bir şekilde indüklemek için önemli olabileceği bildirilmiştir. ${ }^{16}$

Zakrzewska ve ark.'nın kapsamlı çalışmalarının bir basamağında, FGFRl Ser777 fosforilasyonunun biyolojik sonuçlarını araştırmak için, FGFRl'in S777A veya S777D varyantlarını (kontrol U2OSR1 hücrelerine kıyasla) stabil bir şekilde eksprese eden U2OS hücrelerinin (U2OSR1 S777A, U2OSR1 S777D) FGF1'e yanıt olarak çoğalma yeteneğini incelemişlerdir. U2OSR1 WT (aşırı FGFR1 eksprese eden yabanıl tip insan osteosarkom hücre hatt1), U2OSR1 S777A, U2OSR1 S777D (aşırı FGFR1 eksprese eden S777A, S777D mutant insan osteosarkom hücre hatlar1) FGF1 ile muamele edildikten sonra, S777A mutasyonuna sahip hücrelerin çoğaldığını bulmuşlardır. Çalışmanın çeşitli aşamalarında protein ekspresyonları western blot analizi ile değerlendirilmiştir. ${ }^{7}$

Zakrzewska ve ark., fosforile Ser777'nin, FGFR'nin inaktivasyonundan sorumlu tirozin fosfatazlar için bir bağlanma bölgesi olarak hareket edebileceğini bu yüzden Ser777'nin fosforilasyonunun FGFRl'in aktivitesini azalttığını; Ser777 fosforilasyonu engellendiğinde veya alanine dönüştüğünde (S777A mutasyonu) ise, FGFR1 aktivitesinin arttığ1 ve mitojenik sinyallerin harekete geçirildiği, hücrelerin migrasyon yeteneğinin arttığ1, bu durumun da pek çok kanser çeşidi için önemli olabileceği bildirilmiștir. ${ }^{7,17}$ 
Bu durum bize Ser777 mutasyonunun kanserli olgularda DNA dizi analizi yoluyla çalışılabileceğini düşündürmüştür. $\mathrm{Bu}$ kapsamda gerçekleştirdiğimiz çalışmamızda; FGFRl Ser777 mutasyonunun DNA dizi analizi metoduyla incelenerek; olası farklılıkların mesane kanserli hastalar ile kontrol grubunda karşılaştırılması amaçlanmıştır.

\section{Yöntem}

Çalışma kapsamında, Bursa Uludağ Üniversitesi, Tıp Fakültesi, Araştırma Etik Kurulundan 31 Mayıs 2011 tarihli ve 2011-12/6 nolu etik kurul onayı ile katılımcıların bilgilendirilmiş/aydınlatılmış yazılı onamları alınmıştır. Çalışmaya transizyonel hücreli mesane kanserli (TCC) 62 olguya ait parafine gömülü tümör dokusu örneği ve 30 sağlıklı kontrol grubu dahil edilmiștir. Parafine gömülü tümör dokusu örnekleri 10 × 0.5 mikron kesitler halinde alınmış ve genomik DNA izolasyonu QIAamp DNA FFPE Tissue Kit (Qiagen, Dusseldorf, Germany) kullanılarak ve kontrol grubundan 2mL EDTA'lı tüplere alınan periferik kanlardan DNA izolasyonu High Pure PCR Template Preparation Kit (Roche Diagnostics, Mannheim, Germany) kullanılarak, üreticinin talimatları doğrultusunda gerçekleştirilmiştir. İzole edilen genomik DNA, FGFRI Ser777 mutasyonu tespiti için thermal cycler ile amplifiye edilmiştir. PCR ürünlerini temizlemeyi takiben, aynı forward primerler kullanılarak FGFRl Ser777 için sekans PCR'1, Big Dye Terminator v3.1 Cycle Sequencing Kit (Applied Biosystems Inc, Foster City, CA, USA) kullanılarak gerçekleştirilmiştir. FGFRl Ser777 sekans analizi için kapiller elektroforez, ABI PRISM ${ }^{\circledR} 3100$ Genetic Analyzer (Applied Biosystems) cihazıyla yapılmıştır. İstatistiki analiz, SPSS programı (SPSS for Windows Release version 12, SPSS Inc. Headquarters, 223 S. Wacker Drive, 11th floor, Chicago, IL) kullanılarak gerçekleştirilmiştir.

\section{Bulgular}

Çalışmamızda hasta ve kontrol grubu benzer yaş aralığında yer almaktayd1 (hasta grubu 63,34+12,5; kontrol grubu $60,8+11,1 ; p>0,05)$. Mesane kanseri hastaları arasında erkek hastalar daha fazla sayıda iken (55 erkek; 7 kadın), benzer bir dağılım kontrol grubu için de geçerli idi (28 erkek; 2 kadin) ( $p>0,05)$. WHO 2004 mesane kanseri klasifikasyon sistemine göre, 19 düşük riskli kasa invaze olmayan mesane karsinomu, 20 yüksek riskli kasa invaze olmayan mesane karsinomu ve 23 yüksek riskli kasa invaze mesane karsinomu çalışmaya dahil edilmiştir. Mutasyon analizi sonucu, hasta ve kontrol grubunda mutasyon saptanmamış olup, tüm olgu ve kontrol grubu bireyleri (62 transizyonel hücreli mesane kanserli hasta ve 30 sağl1klı kontrol grubu) Ser777 AA genotipi (Çizelge 1) göstermiştir.

Çizelge 1. Ser 777 AA genotipine sahip bir olguya ait sekans grafiği

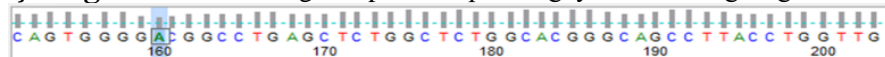

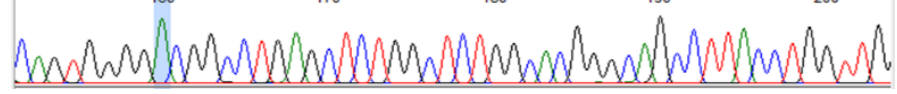

\section{Tartışma}

FGFR sinyalinin hatasız olarak düzenlenmesi hücrenin kaderinin belirlenmesinde önemlidir. Çünkü hücrenin proliferasyon potansiyelini etkileyebilir ve sonuç karsinogenez ve tümör oluşumuyla sonuçlanabilir. Bununla birlikte, FGFRl aktivasyonunun iyi araştırılmış mekanizmasına karşın; reseptör deaktivasyonunu sağlayan mekanizmalar çok iyi anlaşılamamıştır. ${ }^{11}$ Aktive edilmiş bir FGFR tarafından oluşturulmuş bir sinyalin azaltılması, reseptörün lizozomal degredasyonu ve endositozla sağlanabilir. ${ }^{18} \mathrm{Ek}$ olarak, FGF tarafından indüklenmiş sinyalin susturulmasına yol açan bir negatif feedback mekanizmasına, MAPK fosfataz 3 (MKP3), Sprouty (Spry) proteinler ve SEF (FGF'ye benzer ekspresyonu olan) ailesi üyeleri gibi, reseptör sinyalizasyonunu sinyal transdüksiyon yolağının farklı basamaklarında düzenleyen pek çok protein tarafindan aracılık edilir. ${ }^{11,19-21}$

Zakrzewska ve ark.'nın çalışması FGFRl'in ERK-bağımlı Ser777 fosforilasyonunu içeren ve daha önce karakterize edilmemiş bir düzenleyici mekanizmayı ortaya koymuştur. Çalışma, FGFRI'in C-terminal kuyruğunun MAPK'lar olan ERK1 ve ERK2 için direkt substrat olduğunu ve bu kinazların kendi sinyalizasyonlarını FGFRl'in aktivitesini düzenleyerek kontrol ettiklerini belirlemiştir. FGFRl'in Ser777 forforilasyonuna dayanan bu negatif feedback ilmeğinin, proliferasyon sinyallerini kontrol eden kompleks bir sistemin parçası olduğu ve bu sistemin aşırı çalışmasının, kanser gelişimi de dahil olmak üzere tahrip edici olaylara yol açabileceği bildirilmiştir. ${ }^{7}$

Sørensen ve ark.'nın yaptı̆̆ı bir çalışmada, FGFR'nin Cterminal kuyruğunun Ser777'sinin FGF1 translokasyonu için önemli olduğu gösterilmiştir. C-terminal kuyruğunun ilk yarısı iki tirozin ve $11 \mathrm{Ser} / \mathrm{Thr}$ rezidüsü içermektedir. Bu amino asitler, dört FGFR izoformu arasında oldukça iyi korunmuştur. $\mathrm{Bu} \mathrm{Ser} / \mathrm{Thr}$ rezidüleri arasında, içeriğ sebebiyle Ser777, (DQYS777PSF) muhtemel MAPK fosforilasyon bölgesi olarak özel ilgi görmüştür. Ser777, mutasyonla alanine dönüştüğünde, FGF1'in translokasyonu engellenirken, asidik aminoasitler olan aspartik asit veya glutamik aside dönüşecek şekilde mutasyona uğradığında ise; fosforile edilmiş serini taklit edebildiği için FGF1 translokasyonunun gerçekleşmediği bildirilmiştir. $\mathrm{Bu}$ çalışmada, mutant S777D'si olan FGRF1 aracılığıyla gerçekleşen FGF1 translokasyonunun, p38 MAPK aktivitesinden etkilenmediği ortaya konulmuştur. ${ }^{15} \mathrm{Bu}$ durum, p38 MAPK'nin FGF1 translokasyonundaki rolünün, FGFRl'deki Ser777'in fosforilasyonu olduğunu düşündürmüştür. Sørensen ve ark.'nın rekombinant $\mathrm{p} 38 \alpha$ ve rekombinant FGFRl C-terminal kuyruğu kullanılarak gerçekleştirdikleri in vitro çalışmalarında, p38 $\alpha$ yabanıl-tip FGFR1 C-terminal kuyruğunu fosforile edebilirken; FGFR1 S777A veya FGFR1 S777D'lerin C-terminal kuyruğunu fosforile edemediği ortaya konulmuştur. $\mathrm{Bu}$ çalışma, FGFR1 C-terminal kuyruğundaki Ser777'in, p38 $\alpha$ için direkt ve aynı zamanda da tek fosforilasyon bölgesi olduğunu düşündürmüştür. $\mathrm{Bu}$ sonuçlar, FGFR'nin Cterminal kuyruğunun öneminin anlaşılmasını ve bu domainin hücre sinyal olaylarına cevaben reseptör fonksiyonlarını düzenleyebildiği kanısına varılmasını sağlamıştır. ${ }^{15}$

Zakrzewska ve ark. yaptıkları çalışmalarında, FGF1'in FGFR'nin C-terminal kuyruğunda bulunan spesifik bir serin rezidüsünün (Ser777), direkt ERK1/2-arac1lı fosforilasyonunu stimüle ettiğini bulmuşlardır. ${ }^{17} \mathrm{Bu}$ rezidünün fosforilasyonu, reseptörün kinaz domaininde tirozin fosforilasyonunu azaltarak, reseptörün aktivasyonunu bir negatif feedback yoluyla inhibe etmiştir. Çalışma, FGFR1 aktivitesinin kontrolünde daha önce karakterize edilmemiş, potansiyel olarak hücreleri aşırı intraselüler sinyalizasyondan koruyabilecek bir mekanizmayı göstermiştir. ${ }^{17}$ 
Zakrzewska ve ark.'nın FGFRl'i stabil şekilde eksprese eden NIH3T3 fare fibroblastları ve insan osteosarkom U2OS hücre hatlarıyla yaptıkları başka bir çalışmada, ERK1 ve ERK2'ye ek olarak p38 kinazın da FGFR reseptör substrat 2 (FRS2)'yi fosforile edebildiğini göstermişlerdir. ERK1/2 ve p38'in inhibisyonunun, FRS2'nin fosforilasyonunda anlamlı bir değişime yol açarak sırasıyla, FGFRl ve FRS2'nin tirozin fosforilasyonu ve sinyalizasyonun devamlılı̆̆ını sağladığ1 da bu çalışmada gösterilmiştir. ${ }^{17}$ Böylece, Ser777 fosforilasyonunu sağlayan iki yolağın da benzer bir mekanizmadan etkilendiği ortaya konmuştur.

ERK1/2, JNK1/2/3 ve p38 $\alpha / \beta / \gamma / \delta$ kanser alanında çalışılan başlıca MAPK'lardır. ERK yolağı mitojen faktörler tarafından aktive edilir ve bu yolak hücre proliferasyonunda artış ve genellikle apopitozda azalmaya neden olan, kanserde en fazla mutasyona uğrayan yolaklardan biridir. ${ }^{22}$ Diğer yandan, p38 ve JNK yolakları, stres faktörleri tarafından aktive edilirler ve kanserin derecesine, hücre tipine ve MAPK izoformlarına bağlı olarak değişim gösterdikleri halde, kanserdeki rolleri hala tam olarak açıklanamamıştır. ${ }^{23}$

Pek çok çalışma, p38'in antitümörojenik görevi olduğuna dair deneysel kanıt sunsa da, diğer çalışmalar, bu kinazın tümör hücrelerinde surviyi, migrasyonu, kemoterapötik ajanlara direnci artırarak kanseri ilerlettiğini göstermiştir. ${ }^{24}$ P38a'nın bir meme kanseri fare modelinde delesyona uğramasının, DNA hasarına cevabın bozulması ve artmış replikatif stres, DNA hasarı ve kromozom instabilitesine yol açtığı bildirilmiştir. ${ }^{25}$ Yine bir meme kanseri modelinde,

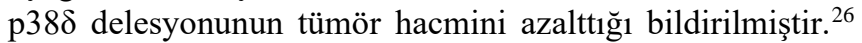
p38'in, tümör promotör rolüyle uyumlu olarak, çalışılan 18 akciğer tümöründe normal dokuya oranla p38 kinaz aktivitesinin arttığ 1 bulunmuştur. ${ }^{27}$ Benzer şekilde, 400'den fazla insan baş-boyun skuamöz hücreli kansinomu (HNSCC) doku örneğinde yapılan immunohistokimyasal analiz, p38'in, olguların \%79'unda hiperaktive edildiğini göstermiştir. ${ }^{28}$ p38 $\alpha$ 'nın tümör baskılayıcı rölüne zıt olarak, p38y'nın Ras mutant kolon kanseri hücrelerinde ekspresyonunun seçici olarak indüklenmiş olduğu ve proliferasyon için gerekli olduğu görülmüş ve böylece p38 izoforma-bağlı mekanizmasının Ras sinyalizasyonuna etki


tümörogenezinde etkili olduğu fare modelinde ortaya konulmuştur. Bu izoform spesifikliği, MCF-7 meme kanseri hücre hattında da ortaya konulmuştur; keza AP-1-bağımlı transkripsiyon ve hücre proliferasyonu p38 $\beta$ tarafindan indüklenirken; $\mathrm{p} 38 \delta$ ve p38 $\gamma$ tarafından inhibe edilmiştir. ${ }^{29}$

\section{Sonuç}

Yapılan çalışmalar incelendiğinde, ERK 1/2 ve p38a'nın, Ser 777'yi fosforile etmek yoluyla antitümörojenik etki gösterdiği anlaşılmaktadır. Bütün bu çalışmalar ve Ser777 fosforilasyonunun FGFRl aktivasyonunu inhibe ettiği göz önüne alındığında, mutasyona uğramasının da aksine FGFRl'i aktive ederek, hücreyi karsinogeneze götürebilecek ve bunu devam ettirebilecek mekanizmaları muhtemel hale getirebileceğini düşündürmektedir. Çalışmamızda, Ser777 mutasyonuyla karsinogenezi tetikleyen mekanizmaların harekete geçebilmesinin gerçekleşmesi hipotezinden yola çıkarak, amino asit değişimlerine yol açacak olası DNA dizi değişimlerinin mesane kanserinde analizi yapılmıştır. Fakat, mesane kanseri tümörlerinde veya kontrol grubunda FGFRl geni Ser777 bölgesinde herhangi bir varyasyon saptanmamıştır. $\mathrm{Bu}$ da bize, Ser777 mutasyonunun, mesane kanserinin oluşum mekanizmasında rol alan bir mutasyon olmadığını düşündürmüştür. Bununla birlikte, diğer kanser türlerinde ve FGFR1 mutasyonlarının etkili olduğu iskelet, olfaktor hastalıkları, metabolik hastalıklar vb.'de FGFRl Ser777 mutasyonunun, daha geniş sayılı olgu gruplarında araştırılmasının değerli bilgiler sağlayabileceği öngörülmüştür.

Açıklamalar

Çalışmamız " 1 st International Congress \& Workshop of Forensic Toxicology-2014” 'te poster olarak sunulmuştur.

\section{Çıkar Çatışması Beyanı}

Yazarlar arasında herhangi bir çıkar çatışması bulunmamaktadır.

\section{Etik Onay/Hasta Onamı}

$\mathrm{Bu}$ araştırma Bursa Uludağ Üniversitesi, Tıp FakültesiAraştırma Etik Kurulunun 31 Mayıs 2011 tarihli ve 201112/6 nolu kurul kararı ile gerçekleştirilmiştir.

\section{Maddi Destek}

$\mathrm{Bu}$ çalışmada herhangi bir fon veya destekten yararlanılmamıştır.

\section{Yazar Katkıları}

AÖ: Fikir; AÖ, HŞ: Tasarım; AÖ, HŞ: Denetleme; MŞ, AŞ, AÖ: Materyal toplanması ve işlenmesi; AÖ, HŞ, DD, Üi: Laboratuvar analizleri; HŞ, MŞ, AÖ: Sonuçların analizi ve yorumlanması; AÖ, DD: Literatür taranması ve kaynak düzenlenmesi; AÖ: Makalenin hazırlanması.

\section{Kaynakça}

1. Andrew AS, Gui J, Hu $\mathrm{T}$ et al. Genetic polymorphisms modify bladder cancer recurrence and survival in a USA population-based prognostic study. BJUI 2014; 115(2): 238247. doi: 10.1111/bju.12641. Epub 2014 Mar 26.

2. Babaian AIU, Kariakin OB, Teplov AA, Zaletaev DV, Nemtsova MV. Some molecular-genetic markers, defining the pathogenesis of superficial and invasive bladder cancer. Mol. Biol 2011;45(6): 929-932 doi.org/10.1134/S0026893311060021.

3. Balbás-Martínez C, Rodríguez-Pinilla M, Casanova A et al. ARID1A alterations are associated with FGFR3-wild type, poor-prognosis, urothelial bladder tumors. PloS one, 2013; 8(5), e62483.

4. Czerniak B, Dinney C, McConkey D. Origins of Bladder Cancer. Аnnu Rev Pathol 2016; 11: 149-174. doi:10.1146/annurev-pathol-012513-104703.

5. Verim L. Mesane Kanseri Gelişiminde Genetik Değişim ve Hedefler. Deneysel Tip Araştırma Enstitüsü Dergisi (Experimed) 2016; 5(10): 67-72.

6. Felsenstein KM, Theodorescu D. Precision medicine for urothelial bladder cancer: update on tumour genomics and immunotherapy. Nat Rev Urol. 2018;15(2):92-111. doi: 10.1038/nrurol.2017.179.

7. Zakrzewska M, Haugsten EM, Nadratowska-Wesolowska B at el. ERK-mediated phosphorylation of fibroblast growth factor receptor 1 on Ser777 inhibits signaling. Sci. Signal 2013; 6(262), ra11. doi.org/10.1126/scisignal.2003087.

8. Furdui CM, Lew ED, Schlessinger J, Anderson KS. Autophosphorylation of FGFR1 kinase is mediated by a sequential and precisely ordered reaction. Mol Cell 2006; 21(5): 711-717 doi.org/10.1016/j.molcel.2006.01.022.

9. Lew ED, Furdui CM, Anderson KS, Schlessinger J. The precise sequence of FGF receptor autophosphorylation is kinetically driven and is disrupted by oncogenic mutations. $\begin{array}{llll}\text { Sci. Signal 2009; } & \text { 2(58): }\end{array}$ doi.org/10.1126/scisignal.2000021. 
10. Eswarakumar VP, Lax I, Schlessinger J. Cellular signaling by fibroblast growth factor receptors. Cytokine Growth $F R$., 2005; 16(2): 139-149 doi.org/10.1016/j.cytogfr.2005.01.001.

11. N. Turner R. Grose, Fibroblast growth factor signalling: From development to cancer. Nat. Rev. Cancer 2010; 10: 116-129 doi: $10.1038 / \mathrm{nrc} 2780$.

12. Wesche J, Haglund K, Haugsten EM. Fibroblast growth factors and their receptors in cancer. Biochem. J 2011; 437(2): 199-213 doi.org/10.1042/BJ20101603.

13. Lax I, Wong A, Lamothe $\mathrm{B}$ et al. The docking protein FRS2alpha controls a MAP kinase-mediated negative feedback mechanism for signaling by FGF receptors. Mol Cell 2002; 10(4): 709-719 https://doi.org/10.1016/s10972765(02)00689-5.

14. Cuadrado A, Nebreda AR. Mechanisms and functions of $\mathrm{p} 38$ MAPK signalling. Biochem. $J$ 2010; 429(3): 403-417 doi.org/10.1042/BJ20100323.

15. Sørensen V, Zhen Y, Zakrzewska M et al. Phosphorylation of fibroblast growth factor (FGF) receptor 1 at Ser777 by p38 mitogen-activated protein kinase regulates translocation of exogenous FGF1 to the cytosol and nucleus. Mol. Cell. Biol 2008; 28(12): 4129-4141 doi.org/10.1128/MCB.02117-07.

16. Kostas M, Lampart A, Bober J, Wiedlocha A, Tomala J, Krowarsch D, Otlewski J, Zakrzewska M. Translocation of Exogenous FGF1 and FGF2 Protects the Cell against Apoptosis Independently of Receptor Activation. J Mol Biol. 2018 Oct 19;430(21):4087-4101. doi: 10.1016/j.jmb.2018.08.004.

17. Zakrzewska M, Opalinski L, Haugsten EM, Otlewski J, Wiedlocha A. Crosstalk between p38 and Erk $1 / 2$ in Downregulation of FGF1-Induced Signaling. Int. J. Mol. Sci 2019; 20(8): 1826 doi.org/10.3390/ijms20081826.

18. Haugsten EM, Malecki J, Bjørklund SM, Olsnes S, Wesche J. Ubiquitination of fibroblast growth factor receptor 1 is required for its intracellular sorting but not for its endocytosis. Mol. Biol. Cell 2008; 19(8): 3390-3403 doi.org/10.1091/mbc.e07-12-1219.

19. Fürthauer M, Lin W, Ang SL, Thisse B, Thisse C. Sef is a feedback-induced antagonist of Ras/MAPK-mediated FGF signalling. Nat. Cell Biol 2002; 4(2): 170-174 doi.org/10.1038/ncb750.

20. Tsang M, Friesel R, Kudoh T, Dawid IB. Identification of Sef, a novel modulator of FGF signalling. Nat. Cell Biol 2002; 4(2): 165-169. https://doi.org/10.1038/ncb749.

21. Cabrita MA, Christofori G. Sprouty proteins, masterminds of receptor tyrosine kinase signaling. Angiogenesis, 2008; 11(1): 53-62 doi.org/10.1007/s10456-008-9089-1.

22. Samatar AA, Poulikakos PI. Targeting RAS-ERK signalling in cancer: promises and challenges. Nat. Rev. Drug Discov 2014; 13(12): 928-942 doi.org/10.1038/nrd4281.

23. Huth HW, Santos DM, Gravina HD et al. Upregulation of p38 pathway accelerates proliferation and migration of MDA-MB231 breast cancer cells. Oncol. Rep 2017; 37(4): 2497-2505 doi.org/10.3892/or.2017.5452.

24. Wagner EF, Nebreda AR. Signal integration by JNK and p38 MAPK pathways in cancer development. Nat. Rev. Cancer 2009; 9(8): 537-549 doi.org/10.1038/nrc2694.

25. Cánovas B, Igea A, Sartori AA et al. Targeting p38 $\alpha$ Increases DNA Damage, Chromosome Instability, and the Anti-tumoral Response to Taxanes in Breast Cancer Cells. Cancer cell 2018; 33(6): 1094-1110.e8 doi.org/10.1016/j.ccell.2018.04.010.

26. Wada M, Canals D, Adada $M$ et al. P38 delta MAPK promotes breast cancer progression and lung metastasis by enhancing cell proliferation and cell detachment. Oncogene 2017; 36(47): 6649-6657 doi.org/10.1038/onc.2017.274.

27. Greenberg AK, Basu S, Hu J et al. Selective p38 activation in human non-small cell lung cancer. Am J Resp Cell Mol 2002; 26(5): 558-564 doi.org/10.1165/ajrcmb.26.5.4689.

28. Leelahavanichkul K, Amornphimoltham P, Molinolo AA, Basile JR, Koontongkaew S, Gutkind JS. A role for p38 MAPK in head and neck cancer cell growth and tumorinduced angiogenesis and lymphangiogenesis. Mol. Oncol 2014; 8(1): 105-118. doi.org/10.1016/j.molonc.2013.10.003.
29. Martínez-Limón A, Joaquin M, Caballero M, Posas F, de Nadal, E. The p38 Pathway: From Biology to Cancer Therapy. Int. J. Mol. Sci 2020; 21(6): 1913 doi.org/10.3390/ijms21061913. 